\title{
Humanização na atenção à saúde e as desigualdades raciais: uma proposta de intervenção'
}

\section{Humanization in health care and racial inequalities: an intervention proposal}

\author{
Luís Eduardo Batista \\ Secretaria de Estado da Saúde de São Paulo, Instituto de Saúde. \\ Núcleo de Serviços e Sistemas de Saúde. São Paulo, SP, Brasil. \\ E-mail: leduळisaude.sp.gov.br

\section{Daphne Rattner} \\ Universidade de Brasília. Faculdade de Ciências da Saúde. Depar- \\ tamento de Saúde Coletiva. Brasília, DF, Brasil. \\ E-mail: daphne.rattnerøgmail.com

\section{Suzana Kalckmann} \\ Secretaria de Estado da Saúde de São Paulo, Instituto de Saúde, \\ Núcleo de Práticas e Programa de Mestrado Profissional em Saúde \\ Coletiva. São Paulo, SP, Brasil. \\ E-mail: suzanakळisaude.sp.gov.br

\section{Maridite Cristóvão Gomes de Oliveira} \\ Hospital Geral de São Mateus e Programa de Mestrado do Instituto \\ de Saúde. São Paulo, SP, Brasil. \\ E-mail: mariditeœuol.com.br
}

\section{Correspondência}

Luís Eduardo Batista

Rua Santo Antônio, 590, 4 andar. São Paulo, SP, Brasil.

CEP $01314^{-000 .}$

\section{Resumo}

O artigo relata a proposta de ação/intervenção "Humanização do parto e nascimento: questões étnico/ racial e de gênero", desenvolvida no Hospital Geral de São Mateus Dr. Manoel Bifulco em São Paulo (SP), que objetivou sensibilizar a equipe do hospital para a mortalidade materna de mulheres negras. Foram utilizados como fontes documentais relatórios de gestão, convênio estabelecido, relatórios de ordenamento de despesas e o livro Nascer com equidade. São descritas as sete etapas desenvolvidas: sensibilização e negociação na Secretaria de Estado da Saúde de São Paulo (SES-SP); negociação com o Ministério da Saúde; sensibilização e pactuação com o serviço de saúde; diagnóstico da situação; sensibilização dos profissionais para as questões de gênero e raça/cor, com a introdução do quesito "cor" nos sistemas de informação; formação dos profissionais do hospital; e formação do movimento social. O projeto teve como resultados a inclusão do quesito "cor" na Autorização de Internação Hospitalar; a sensibilização da equipe para as especificidades da saúde da mulher negra; e a mudança de percepção da equipe em relação à presença do pai na hora do nascimento, gerando a campanha "Pai não é visita”. O projeto foi efetivo na abordagem de temas complexos.

Palavras-chave: Racismo; Humanização da Assistência; Políticas de Saúde; Saúde Reprodutiva; Pesquisa-Ação; Saúde da Mulher.

\footnotetext{
1 Projeto financiado pelo Ministério da Saúde, Secretaria de Atenção à Saúde. Coordenação Geral de Saúde das Mulheres. Fundo Nacional de Saúde/SES São Paulo. Convênio 1504/o6 - 46374-50oooo1/o6-o1o.
} 


\section{Abstract}

The study reports the project "Humanização do parto e nascimento: questões étnico/racial e de gênero" [Humanization of childbirth care: ethnic/ race and gender issues], an action/intervention research developed in the Hospital Geral de São Mateus Dr. Manoel Bifulco, in São Paulo (SP), Brazil. The objective was to sensitize the hospital team about maternal mortality among black women and discuss the impact of racism in health care. The following documents were used as documental sources: management reports, established partnerships, official letters, expenditure reports and the book Nascer com Equidade [Born with equity]. The project's seven stages were: sensitization and negotiation within the Secretaria de Estado da Saúde de São Paulo (SES-SP) [State Secretariat of Health of São Paulo]; sensitization and negotiation with the Brazilian Ministry of Health; sensitization and establishment of an agreement with the health service; diagnosis of the situation in the hospital; sensitizing the professionals towards gender and race issues, introducing the race data collection in the forms of the hospital's data bank; training hospital staff; forming social movements within the neighborhood. The project's results were: the collection of data on race became routine, and prompted the Ministry of Health to adopt this information request in all its forms; professionals were trained in women's health care and sensitized to the specificities of the black population; and there were changes in how the health care team perceives the presence of the father at birth, creating the campaign "Fathers are not visitors". The project was effective in broaching those complex issues and it may be replicated elsewhere.

Keywords: Racism; Humanization of Assistance; Health Policies; Reproductive Health; ActionResearch; Women's Health.

\section{Introdução}

Em 200o, quando foi realizada a Cúpula do Milênio, líderes de 187 países se comprometeram com a Declaração do Milênio, em que são estipulados oito objetivos para construir um mundo mais seguro, próspero e equitativo. Estes foram denominados "Objetivos de Desenvolvimento do Milênio" (ODMs) (UN, 200o). Propunha-se que suas metas - que adotavam 1990 como ano base - fossem alcançadas em 25 anos, ou seja, em 2015.

Segundo o relatório do Programa das Nações Unidas para o Desenvolvimento de 2014, às vésperas da finalização do prazo, o Brasil já teria atingido as metas determinadas para sete dos oito objetivos em 2015, sendo a exceção o quinto ODM: melhorar a saúde materna, cujo principal indicador é a razão de mortalidade materna (RMM) (Brasil, 2014).

A permanência da RMM em patamares acima das metas sugere que as questões referentes à qualidade dos serviços estejam subjacentes a esses níveis elevados do indicador, principalmente aquelas referentes aos processos de assistência. Segundo o Manual dos Comitês de Mortalidade Materna do Ministério da Saúde: “A mortalidade materna é uma das mais graves violações dos direitos humanos das mulheres, por ser uma tragédia evitável em 92\% dos casos, e por ocorrer principalmente nos países em desenvolvimento" (Brasil, 2007, p. 9).

Em geral, a determinação da RMM está associada ao acesso aos serviços, assim como à qualidade da assistência prestada. A assistência à gestação, ao parto e ao puerpério e as desigualdades regionais, sociais, demográficas, econômicas, políticas e culturais foram temas de estudo de vários especialistas em saúde da mulher (Leal; Gama; Cunha, 2005; Lago; Lima, 2009; Kalckamnn et al., 2010; Goes; Nascimento, 2013). Seguindo essa perspectiva, a Coordenadoria de Controle de Doenças da Secretaria de Estado da Saúde de São Paulo identificou para 2005 uma RMM de 41,4 óbitos por 100 mil nascidos vivos (NV), sendo que as mulheres negras (pretas e pardas) morriam 6,4 vezes mais que a média do estado. Já em 2007, a RMM no estado foi de 33,1 por 100 mil NV, sendo 249,79 por 100 mil NV entre as 
mulheres pretas; 54,2 por 100 mil NV entre as pardas; e 29,5 por 100 mil NV entre brancas. Ou seja, a RMM entre as mulheres pretas foi 7,5 vezes maior que a razão estadual e 8,5 vezes a das mulheres brancas, configurando-se em importante expressão das desigualdades existentes com relação à raça/cor (Kalckmann et al., 2010).

A Pesquisa Nacional de Demografia e Saúde (PNDS-1996) evidenciou que a proporção de risco reprodutivo é maior entre as mulheres negras, que iniciam a vida sexual e têm seu primeiro filho mais precocemente. As negras têm menos acesso a anticoncepcionais - compondo a maior parcela de mulheres que nunca usaram algum método contraceptivo ( $8,3 \%$ negras, $4,1 \%$ brancas) - e menor amplitude do mix anticoncepcional, com mais profuso uso da esterilização feminina, e apresentam um percentual mais alto entre as que não fizeram o pré-natal (Perpétuo, 200o).

Com dados da PNDS-2006, Berquó e Lima (2009) constataram que, entre as mulheres menos escolarizadas, mais pobres, negras e não unidas, é maior a parturição e a proporção de indesejabilidade do último filho.

Leal, Gama e Cunha (2005) constataram essa situação desfavorável das mulheres pretas e pardas no município do Rio de Janeiro. Segundo as autoras, no pré-natal, as mulheres negras tiveram menos acesso à atenção considerada adequada de acordo com os padrões estabelecidos pelo Ministério da Saúde. No momento do parto, foram mais penalizadas ao não serem aceitas na primeira maternidade que procuraram e, durante o parto, receberam menos anestesia. As autoras concluíram que essas mulheres sofrem dupla discriminação, individual e institucional, que é pautada na escolaridade e no pertencimento racial.

Dados de estudo realizado por Dinizet al. ${ }^{2}$ a partir da pesquisa "Nascer no Brasil" evidenciam que as mulheres negras tiveram menos acompanhantes na hora do parto; embora a cesárea tenha duplicado entre as mulheres negras, elas tiveram mais partos vaginais, entraram mais frequentemente em trabalho de parto e seus filhos nasceram de termo pleno. Segundo os autores, se trata de uma "inversão da disparidade esperada".
O Sistema Único de Saúde (SUS) propõe ações de saúde dirigidas para o atendimento global das necessidades prioritárias de grupos populacionais específicos, articulando esforços do governo federal, dos estados e municípios, propondo a universalidade considerando todas as fases da vida; assegura o direito de assistência dos níveis menos complexos (UBS e postos de saúde) aos mais complexos (hospitais terciários e quaternários); propõe que a atenção à saúde respeite as especificidades das populações com maior vulnerabilidade; e que se trate igualmente a todos, de forma a promover a justiça e a equidade (Brasil, 2010; Batista; Monteiro, 2010; Barros; Souza Campos; Fernandes, 2014).

Sob a premissa de que as iniquidades raciais interferem na assistência à gravidez, parto e puerpério, assim como no acesso e na qualidade da atenção ofertada às mulheres negras nos serviços de saúde, a partir das evidências dos dados epidemiológicos, os representantes da sociedade civil do Comitê Técnico Saúde da População Negra de São Paulo (CTSPN, instituído pela Resolução SS-oo4, de 13 de janeiro de 2006), especialmente o Instituto AMMA Psique e Negritude, apresentaram à Secretaria de Estado da Saúde de São Paulo (SESSP) uma proposta de pesquisa de ação/intervenção. Nascia, assim, o projeto "Humanização do parto e nascimento: questões étnico/raciais e de gênero".

Este artigo visa a apresentar o projeto, assim como refletir sobre suas potencialidades e limitações.

\section{Metodologia}

Como fontes documentais foram utilizados convênios estabelecidos, ofícios, relatórios de ordenamento de despesas, relatórios de gestão e o livro Nascer com equidade. Também realizou-se uma roda de conversa com a diretora do Hospital Geral de São Mateus (HGSM) e com a diretora do Instituto AMMA Psique e Negritude, instituição que coordenou a intervenção.

A pesquisa de ação/intervenção é uma modalidade de investigação em que o pesquisador, ao

2 DINIZ, C. S. G. et al. Desigualdades sociodemográficas e na assistência à maternidade entre puérperas no Sudeste do Brasil segundo cor da pele: dados do inquérito Nacional Nascer no Brasil (2011-2012). Saúde e Sociedade, São Paulo, v. 25, n. 2, 2016. No prelo. 
mesmo tempo que estrutura novos conhecimentos, também intervém na realidade que vai conhecendo, modificando-a. Segundo Gilles Monceau,

Pesquisa-ação e intervenção não se excluem, elas qualificam a maneira pela qual se constrói e se põe em movimento o dispositivo de trabalho por meio do qual colaboram o(s) pesquisador(es) e os demais que, conforme o caso e o quadro teórico, chamamos de práticos, clientes, parceiros, atores, sujeitos, indivíduos ou pessoas. De parte da pesquisa-ação, a colaboração se coloca de saída em torno de um problema para cujo tratamento se convoca um pesquisador interessado. O fim comum é a produção de conhecimentos novos e até mesmo de instrumentos úteis aos práticos. Porém, como assinala a literatura relativa à pesquisa-ação publicada na França a partir do início da década de 1980, práticos e pesquisadores conservam suas respectivas preocupações. Os conhecimentos produzidos pela colaboração entre eles não são da mesma ordem para um e para o outro, não têm o mesmo uso e não são validados do mesmo modo. De parte da intervenção, o pedido refere-se de início à análise em situação frequentemente por ocasião duma crise em um estabelecimento ou uma organização ou, ainda, de um mal-estar mais difuso sentido por profissionais. Dessa intervenção de intenção analítica, espera-se que provoque uma renovação da percepção que os indivíduos possuem da realidade social em que estão envolvidos. É evidente que a pesquisa-ação tem efeitos de intervenção e a intervenção produz conhecimentos (2005, p. 469).

Esse projeto de pesquisa de ação/intervenção integra o processo de implantação da Política Nacional de Saúde Integral da População Negra (PNSIPN) no estado de São Paulo, iniciado em 2003, entre as atividades descritas como "tecnologias desenvolvidas para subsidiar a implementação da PNSIPN" (Batista; Monteiro, 2010; Batista; Monteiro; Medeiros, 2013, p. 686).
A tramitação para o projeto se iniciou em 2005, mas a realização da pesquisa de ação/intervenção propriamente dita ocorreu no período de janeiro de 2007 a dezembro de 2009 e se concretizou nas etapas:

- $\quad$ sensibilização e negociação no âmbito SES-SP;

- sensibilização e negociação no âmbito do Ministério da Saúde, com vistas ao apoio técnico-financeiro;

- $\quad$ sensibilização e negociação no âmbito de um serviço de saúde, com planejamento participativo;

- diagnóstico e sensibilização dos profissionais e usuários do HGSM para a questão de gênero e raça/cor;

- sensibilização dos profissionais, em uma primeira fase, para incluir "raça/cor/etnia"3 na documentação referente a usuários nos sistemas de informação;

- formação dos profissionais do hospital e de unidades básicas de saúde envolvidos com a atenção à saúde da mulher, aprofundando questões fundamentais para o atendimento mais adequado ao parto e ao nascimento;

- capacitação da sociedade civil, usuários do serviço de saúde e lideranças do movimento negro da comunidade do HGSM, objetivando intervir tanto nos direitos das mulheres, para a saúde da população negra, como na participação social.

Na medida em que, em uma investigação com o delineamento de ação/intervenção, o processo já

\footnotetext{
3 Ao coletar a informação sobre a pessoa ser "branca”, "preta", "parda”, "amarela” ou "indígena”, como utilizado pelo Instituto Brasileiro de Geografia e Estatísticas, especialistas empregam duas denominações: “quesito 'cor”” ou "quesito 'raça/cor/etnia””. Vamos utilizar aqui a denominação "quesito "cor”" para expressar como foi coletada a informação sobre raça/cor/etnia (DIAS; GIOVANETTI; SEABRA SANTOS, 2009).
} 
é, de certa forma, o resultado, o detalhamento da realização será abordado na seção que segue.

\section{Resultados}

\section{Etapa I: sensibilização e negociação no âmbito da Secretaria de Estado da Saúde de São Paulo}

Em 2005, época do início das negociações para a realização deste estudo/intervenção, as áreas técnicas da Secretaria de Estado da Saúde de São Paulo se encontravam desativadas. Em vista dessa realidade, o CTSPN propôs que a atenção à saúde da mulher negra e a discussão de iniquidades raciais e saúde fossem realizadas no âmbito da Política Estadual de Humanização, segundo as diretrizes da Política Nacional de Humanização (PNH) (Brasil, 2004). Foram, então, realizadas reuniões entre os integrantes do comitê e as coordenações do Programa de Humanização da Coordenadoria de Recursos Humanos e da Coordenadoria de Serviços de Saúde da SES-SP. Como o tema era novo e sua relevância ainda não havia ficado completamente estabelecida, as coordenadoras da Política de $\mathrm{Hu}$ manização elencaram suas várias prioridades e propuseram pautar o tema no "II Encontro Temático de Humanização da Secretaria de Estado da Saúde de São Paulo - humanização na atenção e gestão em saúde". Sugeriram, também, inserir as atividades nos dispositivos da PNH já em desenvolvimento na $\mathrm{SES}-S P^{4}$, não reconhecendo, portanto, a necessidade de um investimento específico para lidar com a complexidade do tema.

Para os integrantes do comitê, havia se consolidado um desafio: como evidenciar às coordenadoras de humanização da Coordenadoria de Recursos Humanos e da Coordenadoria de Serviços de Saúde da Secretaria de Estado da Saúde de São Paulo que as desigualdades raciais são fatores estruturantes da sociedade brasileira e que o racismo impacta a saúde de homens e mulheres, brancos, negros, amarelos e indígenas? Como pautar a temática do atendimento inadequado, ineficaz e discriminató- rio no interior do sistema de saúde? Possivelmente, por meio de uma atividade que pudesse ser uma exemplificação prática - e assim o projeto foi tomando corpo.

\section{Etapa 2: sensibilização e negociação no âmbito do Ministério da Saúde com vistas ao apoio técnico-financeiro e ao apoio da Secretaria Estadual}

A proposta do comitê foi apresentada a então área técnica de Saúde da Mulher do Ministério da Saúde em 2006. Ao final desse ano, o secretário de Estado da Saúde assinou o convênio 1504/o6 46374.5000001/o6-010 - Projeto Humanização do Parto e Nascimento e as Questões Étnico-Raciais e de Gênero. Por determinação do Secretário, foi definido que também fosse destinado apoio financeiro da coordenadoria de recursos humanos, com base em horas-aula, para atender às demandas da proposta, e designada uma assessora do gabinete do secretário para acompanhamento de todo o desenvolvimento do projeto.

\section{Etapa 3: sensibilização e negociação no âmbi- to de um serviço de saúde, com planejamento participativo}

Para esse projeto, foi selecionado o HGSM, na cidade de São Paulo (SP), uma vez que nele já havia um Centro de Parto Normal, além do fato de ser um hospital que já realizara vários dispositivos de humanização do parto, do nascimento e aleitamento materno (Silveira et al., 2010).

Constituiu-se um grupo gestor do projeto, integrado pela direção do hospital, a diretoria clínica, a chefia de assistência social, a responsável pelo Centro de Parto Normal, integrantes do Instituto AMMA Psique e Negritude e do Comitê Técnico de Saúde da População Negra (CTSPN/SES-SP). As demais etapas foram acordadas com a direção do HGSM e o grupo gestor, iniciando-se pela sensibili-

4 Os detalhes de cada uma dessas ações, projetos e programas estão descritos no Boletim do Instituto de Saúde. Disponível em: <http:// www.saude.sp.gov.br/resources/instituto-de-saude/homepage/bis/pdfs/bis_n39.pdf>. Acesso em: 16 fev. 2015. 
zação. Esse grupo gestor se reunia periodicamente para trocar ideias sobre a condução do processo, avaliar as atividades realizadas e, se necessário, reorientar seus rumos.

Em janeiro de 2007 foi realizada a palestra de abertura do projeto de ação/intervenção.

\section{Etapa 4: diagnóstico e sensibilização dos pro- fissionais e usuários do HCSM para a questão de gênero e raça - os desafios para implementar o projeto}

Adúvida dos profissionais acerca do debate sobre a saúde da mulher negra ser ou não uma prioridade da SES-SP foi um dos primeiros desafios enfrentados. Assim, nas primeiras reuniões no HGSM, foi necessário mostrar aos profissionais e à sociedade civil que a SES-SP havia "instituído" o CTSPN e a área técnica de Saúde da População Negra e que, apesar de o tema não figurar oficialmente em outras atividades da SES (saúde da mulher, saúde da criança ou humanização), a proposta tinha respaldo do Secretário da Saúde (Batista; Monteiro, 2010; Batista; Monteiro; Medeiros, 2013).

Por outro lado, foi valorizado o fato de que o HGSM era um dos poucos hospitais a possuir um Centro de Parto Normal - uma experiência recém-implantada e inovadora na administração direta da SES-SP.

Um segundo desafio se deu ao ser iniciada a discussão sobre racismo e saúde, utilizando, para isso, a coleta do quesito "cor" nos sistemas de informação do hospital, uma vez que atendentes do serviço de cadastro do hospital precisariam introduzir a pergunta "Qual é a sua cor?".

Segundo a diretora do HGSM:

Apesar de termos distribuído folderes, de existir uma faixa na entrada do hospital com a pergunta "Qual é a sua cor?", os usuários viam a pergunta com desconfiança e aconteceram situações de conflito. Mas quando os jovens acolhedores e as recepcionistas explicavam a proposta, eles imediatamente aderiam. (informação verbal) 5

Um terceiro desafio foi a constatação de que, para se discutir iniquidades de classe, de gênero e raça/etnia de forma a atingir resultados efetivos na redução da mortalidade materna, seria fundamental uma atuação conjunta da atenção básica e de profissionais de saúde da Supervisão de Saúde São Mateus. Todavia, no bairro de São Mateus (São Paulo, SP) esses equipamentos estão sob responsabilidade da administração municipal, e o HGSM é da gestão estadual. Diante do fato de que uma negociação desse porte com o nível central da Secretaria Municipal de Saúde seria demorada e trabalhosa, a direção do Hospital optou por uma pactuação com a Supervisão de Saúde São Mateus, o que possibilitou à equipe do projeto envolver a atenção básica de algumas unidades de saúde e algumas equipes da Estratégia Saúde da Família (ESF). Mas não se conseguiu trabalhar na perspectiva de rede, o que viabilizaria resultados mais efetivos em toda a linha de cuidado à saúde da mulher daquela região.

Durante as oficinas e reuniões para discutir as iniquidades de classe, de gênero e saúde, utilizou-se como estratégia inicial a incorporação de temas como a masculinidade e as desigualdades intragênero (desigualdades dentro das desigualdades). Foram abordados assuntos como a caracterização de atendimentos aos homens no serviço de saúde, a percepção dos profissionais do HGSM sobre o lugar do homem nos serviços de saúde e os atendimentos oferecidos e demandados pela população masculina que acompanha as companheiras gestantes. Nesse processo, contou-se com a parceria do Instituto Papai, de Recife. Foram realizadas oficinas de sensibilização, como a "Homens, sexualidade e saúde pública"; rodas de conversa com o fórum pró-saúde São Mateus; discussão da Política de Saúde do Homem; apresentação e distribuição das peças de difusão de informação elaboradas pelo Instituto Papai para a campanha "Pai não é visita"

5 Todos os trechos de informação verbal citados neste artigo foram retirados de uma reunião realizada com Maridite Cristóvão Gomes de Oliveira, diretora do Hospital Geral de São Mateus (HGSM). 
(fôlder, cartazes, camisetas e spot) e apresentação e discussão do fôlder "Política de Atenção Integral à Saúde dos Homens”.

Para a diretora do HGSM:

Só no final do projeto é que fomos perceber que, se antes existia no hospital "O cantinho da mamãe" - que era uma sala ou local de amamentação -, com a inserção da temática da paternidade, o local passou a ser "Recanto da Mamãe e do Papai". O pai passou a ser objeto das orientações nas consultas, inclusive na orientação sobre o aleitamento materno; o hospital passou a ter homens como acompanhantes na sala de parto. Vale destacar que, hoje, o pai é convidado a cortar o cordão umbilical e a receber a criança; a pediatra divide o acolhimento dessa criança com o pai, ou seja, há uma significativa mudança do olhar e da ação da equipe em relação à participação do pai na hora do nascimento. Esse foi um dos resultados não esperados, mas com resultados evidentes na vida afetiva de todas e todos os envolvidos com a chegada da criança no âmbito familiar. (informação verbal)

Segundo ela, ao incluir o pai na maternidade, atualmente o HGSM convive com o acompanhante, e o hospital teve que se adequar, inclusive do ponto de vista estrutural:

Por fim [...] Se não podemos ter hospitais públicos com apartamentos, então, que se criem maternidades com enfermarias de, no máximo, dois leitos, com divisória no meio para assim acolhero acompanhante. Nos novos hospitais, não dá para eles serem construídos com enfermarias/maternidades de quatro leitos, pois isso impossibilita a presença do acompanhante junto da mulher. Nos hospitais com quatro leitos, a solução é comprar divisórias/biombos para esses quartos e, assim, possibilitar que esses homens acompanhem suas companheiras. (informação verbal)

A Lei $\mathrm{n}^{0}$ 11.108, de 7 de abril de 2005 (Brasil, 2005), estipula que toda parturiente tem direito à presença de acompanhante de sua escolha durante o trabalho de parto, no parto e no pós-parto imediato; porém, há uma disjunção entre a lei e a prática concreta (Diniz et al., 2014). O projeto explicitou esse problema e o hospital teve que responder a essa necessidade, uma vez que, na proposta de humanização, deve constar o acolhimento dessa nova pessoa que está chegando - acolhimento esse que tem o grande potencial de melhorar a relação afetiva da família com a criança recém-nascida, devendo haver um compromisso com a qualificação da ambiência para melhorar o atendimento a toda a família, sendo o pai da criança essencial.

\section{Etapa 5: sensibilização dos profissionais para a implementação do quesito "cor" nos sistemas de informação}

Em seguida ao desenvolvimento do tema iniquidades de classe, gênero e saúde, foram iniciadas as rodas de conversa sobre o tema "questões étnicas/raciais e saúde”, e se investiu na formação para implementação do quesito "cor" nos sistemas de informação. Durante as primeiras oficinas, os profissionais se mostraram incomodados com a apresentação dos dados epidemiológicos segundo raça/cor - índices que mostravam desigualdades socioeconômicas, de condições de vida, acesso a bens de consumo, maior mortalidade por Aids, tuberculose, causas externas, mortalidade infantil e materna, entre outros indicadores. Diante dessa constatação, a diretora do HGSM propôs que se desse início à coleta do quesito "cor" na documentação de usuários a fim de se obterem dados locais e dar concretude às questões e dúvidas dos profissionais.

Como esse dado não constava nos cadastros de clientes das diversas áreas do hospital, foi produzido um carimbo com a pergunta "Qual é a sua cor?", a ser utilizado em todos os documentos, dando início à coleta. Com isso, os profissionais começaram a vivenciar conflitos com os usuários e, ainda, puderam observar reações preconceituosas de alguns colegas, tendo surgido, inclusive, cartas anônimas de denúncia de racismo.

A implantação da coleta do quesito "cor" trouxe à luz os preconceitos e processos discriminatórios vivenciados pelos profissionais do hospital, ou seja, 
o racismo interpessoal, tirando da invisibilidade um problema real. Nesse momento, os dados epidemiológicos começaram a dialogar com o desconforto vivenciado pela instituição, com as resistências internas das pessoas e com os preconceitos. Enfim, as experiências de racismo e os indicadores passaram a fazer sentido para aqueles que estavam envolvidos no projeto.

A etapa "Inclusão do quesito "cor" no sistema de informação do HGSM também evidenciou a necessidade de pactuar na Comissão Intergestores Bipartite (CIB) a inclusão do quesito nos Sistema de Informação da Autorização de Internação Hospitalar (AIH) e no Sistema de Informação Ambulatorial (SIA). Assim, a Área Técnica de Saúde da População Negra da SES elaborou uma nota técnica que, aprovada na Comissão Intergestores Bipartite, em 16 de agosto de 2007, foi posteriormente aprovada na Comissão Intergestores Tripartite. Essa iniciativa, somada a outras solicitações do movimento negro, fez que o Ministro da Saúde assinasse a Resolução que incluiu o quesito "cor" no Sistema de Informação Ambulatorial e Hospitalar, conforme a Portaria $\mathrm{n}^{0} 719$, de 28 de dezembro de 2007. Diante disso, desde janeiro de 2008, todos os serviços do país que realizam internações hospitalares têm que coletar a informação "raça/cor/etnia”. Ou seja, esse projeto piloto no HGSM, após apenas um ano de seu início, já tinha um resultado concreto incorporado pelo SUS.

A sensibilização e formação para que se pudesse pôr em prática a coleta da informação "raça/cor/ etnia" tiveram como público as direções técnicas da recepção, registro geral (internação e recepção pronto-socorro), ambulatório, remoção, enfermaria, ouvidoria e Serviço de Arquivo Médico e Estatística (SAME). Foram quatro turmas de 20 horas-aula, com 25 participantes cada, totalizando 100 participantes. Foram realizadas cinco oficinas de quatro horas para cada turma, totalizando 20 oficinas e 80 horas-aula.

A discussão sobre o impacto do racismo na saúde, ocorrida enquanto se implantava o quesito "cor" nos sistemas de informação, provocou mudanças evidentes de postura de algumas pessoas. Segundo a diretora do HGSM: "Hoje, podemos dizer que o tema racismo institucional está pautado no Hospital
Geral de São Mateus, mas precisamos retomar este tema diariamente, como se fosse uma atualização ou uma avaliação de processo" (informação verbal).

O desconhecimento dos profissionais sobre a metodologia da coleta do quesito "cor", como observado no Sistema de Informações sobre Nascidos Vivos (Sinasc) e outros, evidencia que o Ministério da Saúde precisa elaborar e distribuir um manual para esclarecer os funcionários dos diferentes serviços sobre a relevância da informação relativa à raça/cor/etnia.

Essa etapa de sensibilização inicial para os temas "gênero" e "raça/cor", quando somada à etapa de implantação do registro do quesito "cor" na documentação do projeto "Humanização do parto...", foi uma experiência prática e concreta de como trabalhar os temas desigualdades de gênero, saúde do homem, masculinidades, iniquidades raciais em saúde e o impacto do racismo na saúde com profissionais da atenção.

Outro resultado positivo dessa etapa do projeto foi mostrar que há estratégias que podem ser desenvolvidas para atingir um dos fundamentos da PNH, que é reconhecer a diversidade do povo brasileiro e oferecer a todos a mesma atenção à saúde, sem distinção de idade, raça/cor ou etnia, origem, gênero e orientação sexual.

Um tema adicional que surgiu ao se discutir a PNSIPN foi o do respeito à religiosidade do paciente, uma vez que uma das diretrizes dessa política é “o reconhecimento dos saberes e práticas populares de saúde, incluindo aqueles preservados pelas religiões de matrizes africanas" (Brasil, 2013, p. 19). Ao se fazer essa discussão, o grupo pautou o tema "laicidade do Estado". Discutiu-se, então, a possibilidade de haver discriminação religiosa, pois, se lideranças religiosas das igrejas católica e protestantes têm o direito de visitar seus fiéis, por que o mesmo não acontecia com religiosos de matriz africana? E mais, ocorre que muitos pacientes que professam determinadas religiões muitas vezes recebem visitas de religiosos de fé que não a sua. Essa discussão levou o HGSM a montar uma estratégia para que os pacientes tivessem sobre suas camas uma identificação determinando seu credo e indicando se aceitariam ou não receber visita de um religioso. 
Outro ponto a destacar é que os atos religiosos e celebrações realizados no HGSM passaram a adotar o termo "inter-religioso" em vez de "ecumênico", abrigando outras crenças, além das convencionais cristãs no país, como budismo, xamanismo e as religiões afro-brasileiras.

\section{Etapas 6 e 7: formação dos profissionais de saúde e da sociedade civil}

Para a formação dos profissionais de saúde, foi realizado, no Centro de Formação para o SUS, o curso "Saúde da mulher, humanização no parto e nascimento: questões raciais e de gênero", que teve duração de 40 horas-aula e do qual participaram 60 servidores envolvidos diretamente com a atenção à saúde da mulher no HGSM (incluindo o Centro de Parto Normal), nas unidades básicas de saúde da área de abrangência do hospital, além da Supervisão de Saúde São Mateus. Entre os profissionais de saúde, havia médicos, enfermeiros, psicólogos e assistentes sociais.

Por se tratar de projeto piloto, foram convidados docentes com ampla experiência em ministrar esses temas para profissionais de saúde. Entre os temas abordados, constaram: "características sociodemográficas da população negra paulista”; "mortalidade materna: determinantes sociopolíticos, responsabilidade social, prevenção"; "mortalidade materna"; "distúrbios hemorrágicos no ciclo gravídico-puerperal”; "atenção humanizada ao abortamento inseguro e redução da mortalidade materna"; "anemia falciforme na gestação"; "diabete gestacional”; "aspectos emocionais do puerpério”; "transmissão vertical do HIV, sífilis e hepatite B".

Na sequência dessa etapa, foi realizado, no auditório do HGSM, o curso de qualificação para o controle social "Informar, diagnosticar e intervir - Saúde da população negra e participação social”, destinado, prioritariamente, às lideranças do movimento negro, conselheiros do Conselho Gestor da Supervisão de Saúde de São Mateus e dos conselhos gestores do sistema de saúde da zona leste (unidades básicas, AMA etc.), que teve 40 horas-aula e 40 participantes.
Os resultados dessas etapas do projeto foram sistematizados no livro Nascer com equidade: humanização do parto e do nascimento, questões raciais/ cor e de gênero ${ }^{6}$, cujos capítulos são compostos pelos textos e apresentações dos professores (em Powerpoint), oportunizando, assim, um guia para multiplicadores. Essa etapa do projeto também foi registrada no documentário (DVD) denominado $\mathrm{Hu}$ manização do parto e nascimento: questões étnico/ raciais e de gênero (Batista, 2010).

Outro resultado positivo é que, além das evidências científicas referentes à saúde da mulher negra, o curso para profissionais também discutiu a temática do racismo e saúde. Um dos ganhos dessa etapa para a atenção à saúde das famílias atendidas no São Mateus foi o início de um trabalho de acompanhamento dos casos de resultado positivo para doença falciforme na triagem neonatal - no "teste do pezinho". Quando o resultado do exame é positivo, os pais são chamados e o bebê é encaminhado para acompanhamento por hematologista do hospital; nos casos de traço falciforme, a família é orientada e esclarecida sobre a questão. Geralmente, essa é uma atribuição do Serviço de Referência à Triagem Neonatal; todavia, a equipe do hospital chamou para si a responsabilidade.

A discussão sobre as responsabilidades da sociedade civil (usuários do sistema) e movimento social também pode ser considerada mais um ganho do projeto.

\section{Discussão}

Uma das primeiras constatações é a invisibilidade do racismo na sociedade e, por consequência, seu reflexo nos serviços de saúde. Dados produzidos por instituições de pesquisa evidenciam que as desigualdades raciais estão presentes em nossa sociedade e que as mulheres negras são suas maiores vítimas; que as desigualdades raciais interferem no acesso e na qualidade da atenção ofertada às mulheres negras na assistência à gravidez, parto e puerpério. Para Perpétuo (200o) e Diniz et al. (2016), parece existir um abismo que separa as mulheres

6 Disponível em: <http://www.saude.sp.gov.br/resources/ses/perfil/profissional-da-saude/grupo-tecnico-de-acoes-estrategicas-gtae/ saude-da-populacao-negra/livros-e-revistas/nascer_com_equidade_.pdf >. Acesso em: 16 fev. 2015. 
negras da posição que, embora ainda precária em muitos sentidos, já foi alcançada pelas mulheres brancas de classe média. Mesmo havendo fortes evidências de seu impacto na saúde das pessoas e na atenção à sua saúde, o não reconhecimento da relevância de se abordar essa temática foi encontrado tanto no nível central da SES-SP, nas coordenações da política de humanização, como entre os prestadores de cuidados no ambiente hospitalar. Santos e Santos (2013), investigando a percepção de profissionais da atenção primária sobre a PNSIPN, relatam que "as narrativas de profissionais trouxeram à tona que a política para a população negra não deve representar responsabilidade social. É vista como desnecessária e promotora de discriminação" (p. 563). Rinehart (2013), estudando o discurso do sujeito coletivo presente nas falas de secretários municipais de saúde, detectou que há reconhecimento da relevância da PNSIPN, mas há discursos antagônicos quanto à sua pertinência, assim como há representações antagônicas quanto às dificuldades e facilidades na efetivação dessa política.

Na medida em que essa iniquidade se expressa em taxas maiores de mortalidade e de adoecimento, e considerando, ainda, o fato de que o racismo em si modifica o cuidado prestado nos serviços de saúde, urge construir essa consciência, modificando as atitudes e as práticas (Perpétuo, 20oo; Kalckmann et al., 2007; Batista; Monteiro, 2010; Goes; Nascimento, 2013). Neste projeto, a discussão sobre o quesito "cor" possibilitou dialogar com os profissionais de saúde para que reconhecessem a diversidade do povo brasileiro e a necessidade de oferecer a todos a mesma atenção à saúde, sem distinção de idade, raça/cor/etnia, origem, gênero, religião e orientação sexual. É fundamental que a discussão dos aspectos relativos à diversidade - para a compreensão das diferenças, de forma que não resultem em discriminação - sejam conteúdos de projetos pedagógicos da educação permanente, de programas de curso a planos de aula.

Uma decorrência natural dessa necessidade de visibilidade é a universalização da coleta da informação raça/cor/etnia nos sistemas de informação de saúde. Braz et al. (2013), avaliando a completude de preenchimento do quesito "cor" em vários siste- mas de informação do SUS e buscando analisar os 24 indicadores que entram na composição do Índice de Desempenho do SUS (IDSUS), identificaram que apenas três deles poderiam ser validados, prejudicando, assim, a análise desse índice segundo categorias de raça/cor/etnia. No caso específico do SIH, para cuja inserção do quesito houve contribuição deste projeto, a proporção média de preenchimento no triênio de 2010 a 2012 foi 65,1\%. Para esses autores,

Isso implica a dificuldade atual de se dimensionar o desempenho do SUS em relação ao princípio da equidade da atenção à saúde com recorte étnico-racial. Especificamente, daquele grupo alcançado pela Política Nacional de Saúde Integral da População Negra (Braz et al., 2013, p. 559).

A PNDS 2006 identificou que, um ano após a promulgação da Lei $n^{0} 11.108$ (Brasil, 2005), apenas $16 \%$ das parturientes tiveram seu direito a acompanhante respeitado. O inquérito "Nascer no Brasil", cuja coleta de dados ocorreu em 2011 e 2012, isso é, seis anos após a lei, mostrou que, para a maioria das mulheres, seu direito à presença de acompanhante ainda não é garantido nos serviços de saúde, tanto públicos como privados: apenas $18,7 \%$ das mulheres tiveram acompanhante em todos os momentos, e 24,5\% delas não o tiveram em nenhum momento. Entre os fatores de risco para não ter acesso a esse direito, estava o fato de a mulher ser parda (Diniz et al., 2014).

Nessa pesquisa de ação/intervenção, houve um amplo trabalho de envolvimento e sensibilização dos profissionais, com aprofundamento da discussão sobre a paternidade e as masculinidades - "Pai Não é Visita" - para o qual o Instituto Papai deu uma contribuição fundamental (Medrado; Azevedo; Lyra, 2008). Dessa abordagem, resultou o acolhimento ao pai pelo serviço, o reconhecimento da necessidade de adequação da estrutura e a atualização da denominação do "cantinho da mamãe" para "recanto da mamãe e do papai". Ademais, profissionais, gestores e sociedade civil começaram a rever suas relações interpessoais, investir no melhor acolhimento à criança, ter a presença do pai no acolhimento do bebê, investir na melho- 
ria da relação intrafamiliar (com o programa "Pai Não é Visita!"), qualificar a ambiência e melhorar as condições de trabalho e de atendimento aos cidadãos. A literatura referente à importância de acompanhante da escolha da parturiente (Medrado; Azevedo; Lyra, 2008; Diniz et al., 2014), assim como as evidências científicas de seus benefícios, motivou a criação da Lei $n^{0} 11.108$, de 7 de abril de 2005 (Brasil, 2005), e foi importante que, no âmbito de um projeto que discute as relações interpessoais mediadas por discriminação e racismo, fosse incorporada a possibilidade de seu cumprimento.

Ainda em termos de cumprimento de leis, o Estatuto da Igualdade Racial, ou Lei $\mathrm{n}^{0} 12.288 \mathrm{de}$ 2010 (Brasil, 2010), em seu art. 25, dispõe que "É assegurada a assistência religiosa aos praticantes de religiões de matrizes africanas internados em hospitais ou em outras instituições de internação coletiva, inclusive àqueles submetidos a pena privativa de liberdade".

Este projeto antecipou o proposto nessa Lei, na medida em que houve interação da direção do HGSM com as lideranças de várias religiões, incluindo as de matriz africana. 0 respeito a crenças como budismo, xamanismo e religiões afro-brasileiras está configurado nas celebrações inter-religiosas organizadas pela direção daquele hospital e na atenção às pessoas. Este projeto ampliou a visão sobre o tema no HGSM, desenvolvendo mecanismos elaborados pelo conjunto da comunidade hospitalar (gestores, profissionais, usuários) para que a instituição pudesse ter uma postura mais humanizada e acolhedora dessas especificidades. Adicionalmente, houve reconhecimento de que uma mudança cultural em um serviço envolve toda a rede de que ele faz parte, ou seja, no caso da atenção ao parto, os serviços de atenção primária responsáveis pelo atendimento ao pré-natal, ao puerpério e ao acompanhamento da criança nos primeiros anos de vida.

Quanto às suas limitações, o projeto foi pontual, com início e fim, e ficou evidenciado que, quando se trabalha com mudança cultural, há necessidade de manter o estímulo à reflexão, ou seja, é necessária alguma forma de continuidade, e se recomenda que seja prevista em futuros projetos. Outra limitação se refere ao fato de o projeto ter sido realizado em um período de 24 meses, de janeiro de 2007 a dezembro de 2009, um período muito longo, o que prejudica sua ampla reprodutibilidade em uma Secretaria de Estado, que possui 62 hospitais ligados à administração direta.

\section{Considerações finais}

O projeto "Humanização do parto e nascimento: questões raciais e de gênero" surgiu da necessidade de integrantes do CTSPN/SES-SP de discutir os temas da mortalidade materna mais elevada entre as mulheres negras e a relação entre racismo e saúde (impacto do racismo na saúde) com diferentes áreas da SES-SP.

Para poder ser viabilizada, essa proposta contou com o apoio direto do secretário de estado da saúde, concretizado na formalização de convênio com o Ministério da Saúde, definição de recursos (hora-aula) e indicação de interlocução do Gabinete, para acompanhamento de todo o projeto.

A partir das estratégias estabelecidas para a intervenção, realizadas de forma democrática, com oficinas e rodas de conversa que abordaram uma variada gama de temas - desde a mortalidade materna até as masculinidades, passando pelo racismo - foi possível aprofundar com os profissionais de saúde a necessidade de ver as desigualdades existentes dentro das desigualdades, e evidenciar as consequências de um atendimento inadequado, ineficaz e discriminatório no sistema de saúde. E a partir das oficinas e rodas de conversa com a sociedade civil sobre mortalidade materna, a eficácia da participação da sociedade civil e do controle social, direito à saúde e participação social, foi possível ter lideranças do movimento social do entorno do hospital, sensibilizadas e atentas para o exercício e defesa dos direitos dos cidadãos.

Como relatado, essa realização aportou vários resultados alentadores. Dentre eles, cabe salientar que não apenas o quesito "cor" foi incorporado nos sistemas de informação do hospital, mas também a experiência do HGSM motivou discussão a respeito na Comissão Intergestores Bipartite do Estado de 
São Paulo e na Comissão Intergestores Tripartite, passando a integrar a coleta sistematizada de dados do Sistema de Informação Hospitalar já em 2008.

Outro resultado importante foi a sistematização do processo educativo em dois produtos: no DVD Questões étnico/raciais: parto e nascimento e no livro Nascer com equidade: humanização do parto e nascimento, questões raciais/cor e gênero.

Entre os resultados não esperados, cabe destacar:

- a mudança na percepção da equipe da maternidade em relação ao pai no acolhimento do bebê;

- o investimento na adequação do espaço nos leitos das enfermarias da maternidade, para incluir o pai;

- a mudança na denominação da sala, de “cantinho da mamãe" para "recanto da mamãe e do papai";

- o fato de o serviço abrigar, para além de evangélicos e católicos, outras crenças como as religiões afro-brasileiras, o budismo e o xamanismo; e de possibilitar aos pacientes que haja sobre suas camas a identificação de seu desejo de receber (ou não) visitas de algum religioso e, se sim, de qual credo.

- adicionalmente, é necessário reconhecer a multidimensionalidade do alcance deste projeto. Com essa atuação, foi possível:

- modificar a gestão do cuidado, introduzindo a possibilidade de maior qualificação e humanização na assistência à gravidez, parto e puerpério das usuárias do HGSM, salientando-se o reconhecimento e a garantia do direito à presença do pai/acompanhante e do exercício do credo, inclusive para religiões de matriz africana;

- modificar e democratizar a gestão do serviço, com a organização do Grupo Gestor, em que as propostas são coletivamente avaliadas e a decisão de sua execução é compartilhada;

- iniciar um diálogo para a modificação da gestão do sistema, visando à estruturação da rede de atenção.

Ainda que inicial e insipiente, foi aberta a possibilidade de interlocução entre serviços de diferentes esferas, municipal e estadual.

O projeto se propôs a discutir o tema "mortalidade materna de mulheres negras" e a relação entre racismo e saúde. Para atingir esse objetivo, construiu uma metodologia e uma trajetória pelo direito à saúde e pelo regate da cidadania. Os resultados obtidos e os resultados não esperados colocam o projeto em outro patamar, pois ele evidencia que, ao se pautar a temática das desigualdades raciais na perspectiva dos direitos, todos ganham, sejam religiosos ou não: pais, mães e crianças; homens, mulheres, gays, transexuais e transgêneros; negros, brancos, amarelos e indígenas; jovens e idosos; e toda a sociedade.

\section{Referências}

BARROS, S.; SOUZA CAMPOS, P. F. de; FERNANDES, J. J. S. Apresentação. In: BARROS, S.; SOUZA CAMPOS, P. F. de; FERNANDES, J. J. S. (Org.). Atenção à saúde de populações vulneráveis. Barueri: Manole, 2014.

BATISTA, L. E.; MONTEIRO, R. B. Política de saúde da população negra no estado de São Paulo: focalizando para promover a universalização do direito à saúde? Boletim do Instituto de Saúde. São Paulo v.12, n. 2, p. 172-178, 2010.

BATISTA, L. E. (Coord.). Humanização do parto e nascimento: questões étnico/racial e de gênero. Coordenação de Luis Eduardo Batista. São Paulo: Instituto de Saúde, 2010. (17 min). Disponível em: <https://www.youtube.com/watch?v=nıI-3mxbtQ>. Acesso em: o1 ago. 2016.

BATISTA, L. E.; MONTEIRO, R. B.; MEDEIROS, R. A. Desigualdades raciais e saúde: o ciclo da política de saúde da população negra. Saúde em 
Debate, Rio de Janeiro, v. 37, n. 99, p. 681-69o, 2013.

BERQUÓ, E.; LIMA, L. P. de. Planejamento da fecundidade: gravidez não-desejada - PNDS 199620o6. In: BRASIL. Ministério da Saúde. Pesquisa Nacional de Demografia e Saúde da Criança e da Mulher - PNDS 2006: dimensões do processo reprodutivo e da saúde da criança. Brasília, DF: Ministério da Saúde 2009.

BRASIL. Ministério da Saúde. Programa Nacional de Humanização: documento básico para gestores e trabalhadores do SUS. Brasília, DF: Ministério da Saúde, 2004.

BRASIL. Ministério da Saúde. Política Nacional de Saúde Integral da População Negra: uma política do SUS. 2. ed. Brasília, DF: Ministério da Saúde, 2013.

BRASIL. Lei $\mathrm{n}^{0}$ 11.108, de 7 de abril de 2005. Altera a Lei $n^{0} 8.080$, de 19 de setembro de 1990, para garantir as parturientes o direito à presença de acompanhante durante o trabalho de parto, parto e pós-parto imediato, no âmbito do Sistema Único de Saúde - SUS. Diário Oficial União, Brasília, DF, 8 abr. 2005. Disponível em: <http://www.saude.sp.gov.br/resources/ ces/homepage/acesso-rapido/cartilhas-aosconselheiors/cartilha_principais_legislacoes. pdf $>$. Acesso em: 22 jan. 2015.

BRASIL. Ministério da Saúde. Manual dos Comitês de Mortalidade Materna. 3. ed. Brasília, DF: Ministério da Saúde, 2007.

BRASIL. Lei ${ }^{0} 12.288$, de 20 de julho de 2010. Institui o Estatuto da Igualdade Racial; altera as Leis nos 7.716, de 5 de janeiro de 1989, 9.029, de 13 de abril de 1995, 7.347, de 24 de julho de 1985, e 10.778, de 24 de novembro de 2003. Diário Oficial União, Brasília, DF, 21 jul. 2010. Disponível em: <http://www.planalto.gov.br/ccivil_03/_at020072010/2010/lei/l12288.htm>. Acesso em: 1 ago. 2016.

BRASIL. Presidência da República. Objetivos de Desenvolvimento do Milênio: relatório nacional de acompanhamento. Brasília, DF, 2014. Disponível em: <http://www.pnud.org.br/Docs/5_ RelatorioNacionalAcompanhamentoODM.pdf>. Acesso em: 14 jan. 2015.
BRAZ, R. M. et al. Avaliação da completude da variável raça/cor nos sistemas nacionais de informação em saúde para aferição de equidade étnico-racial em indicadores usados pelo Índice de Desempenho do Sistema Único de Saúde. Saúde em Debate, Rio de Janeiro, v. 37, n. 99, p. 554-562, 2013.

DINIZ, C. S. G. et al. Implementação da presença de acompanhantes durante a internação para o parto: dados da pesquisa nacional Nascer no Brasil. Cadernos de Saúde Pública, Rio de Janeiro, v. 30, p. S140-S153, 2014. Suplemento 1.

GOES, E. F.; NASCIMENTO, E. R. Mulheres negras e brancas e os níveis de acesso aos serviços preventivos de saúde: uma análise sobre as desigualdades. Saúde em Debate, Rio de Janeiro, v. 37, n. 99, p. 571-579, 2013.

KALCKMANN, S. et al. Racismo institucional: um desafio para a equidade no SUS? Saúde e Sociedade, São Paulo, v. 16, n. 2, p. 146-155, 2007.

KALCKMANN, S. et al. (Org.). Nascer com equidade: humanização do parto e do nascimento questões raciais/cor e de gênero. São Paulo: Instituto de Saúde, 2010. (Temas em Saúde Coletiva 11).

LAGO, T. D. G.; LIMA, L. P. Assistência à gestação, ao parto e ao puerpério: diferenças regionais e desigualdades socioeconômicas. In: BRASIL. Ministério da Saúde. Pesquisa Nacional de Demografia e Saúde da Criança e da Mulher - PNDS 2006: dimensões do processo reprodutivo e da saúde da criança. Brasília, DF: Ministério da Saúde 2009.

LEAL, M. C.; GAMA, S. G. N.; CUNHA, C. B. Desigualdades raciais, sociodemográficas e na assistência ao pré-natal e ao parto, 1999-2001. Revista de Saúde Pública, São Paulo, v. 39, n. 1, p. 100-107, 2005.

MEDRADO, B.; AZEVEDO, M.; LYRA, J. Rompendo barreiras culturais, institucionais e individuais no cuidado infantil: pai não é visita! Pelo direito de ser acompanhante. In: SEMINÁRIO INTERNACIONAL FAZENDO GÊNERO, 8., 2008, Florianópolis. Anais eletrônicos... Florianópolis: UFSC/Mulheres, 2008. Disponível em: <http:// 
www.fazendogenero.ufsc.br/8/sts/ST21/MedradoAzevedo-Lyra_21.pdf>. Acesso em: 26 jun. 2014.

MONCEAU, G. Transformar as práticas para conhecê-las: pesquisa-ação e profissionalização docente. Educação e Pesquisa, São Paulo, v. 31, n. 3, p. 467-482, 2005 .

PERPÉTUO, I. H. O. Raça e acesso às ações prioritárias na agenda da saúde reprodutiva. Jornal da Rede Saúde, n. 22, p. 67-77, 2000. Disponível em: <http://www.redesaude.org. br/home/conteudo/biblioteca/biblioteca/ jornal/oo6.pdf>. Acesso em: 14 jan. 2015.

RINEHART, D. Política Nacional de Saúde Integral da População Negra: discursos da gestão municipal do SUS. 2013. Dissertação (Mestrado em Ciências da Saúde) - Universidade de Brasília, Brasília, DF, 2013.
SANTOS, J. E.; SANTOS, G. C. S. Narrativas dos profissionais da atenção primária sobre a política nacional de saúde integral da população negra. Saúde em Debate, Rio de Janeiro, v. 37, n. 99, p. 563-570, 2013 .

SILVEIRA, K. F. et al. Mudanças de paradigma na assistência ao parto no SUS: a experiência no Hospital Geral de São Mateus. In: KALCKMANN, S. et al. (Org.). Nascer com Equidade: humanização do parto e do nascimento questões raciais/cor e de gênero. São Paulo: Instituto de Saúde, 2010. p. 73-84. (Temas em Saúde Coletiva 11).

UN - UNITED NATIONS. The Millenium Development Goals. New York, NY: UN Department of Public Information, 2000. Disponível em: <http://bit.ly/1F2acgA>. Acesso em: 14 jan. 2015.

\section{Contribuição dos autores}

Batista e Oliveira participaram de todas as etapas do projeto. Kalckmann e Rattner participaram da concepção e redação do artigo.

\section{Agradecimentos}

Maria Lucia da Silva e Jussara Dias do Instituto AMMA Psique e Negritude, que atuaram em todas as etapas do projeto de ação/ intervenção

Recebido: 21/02/2015

Aprovado: 17/03/2015 